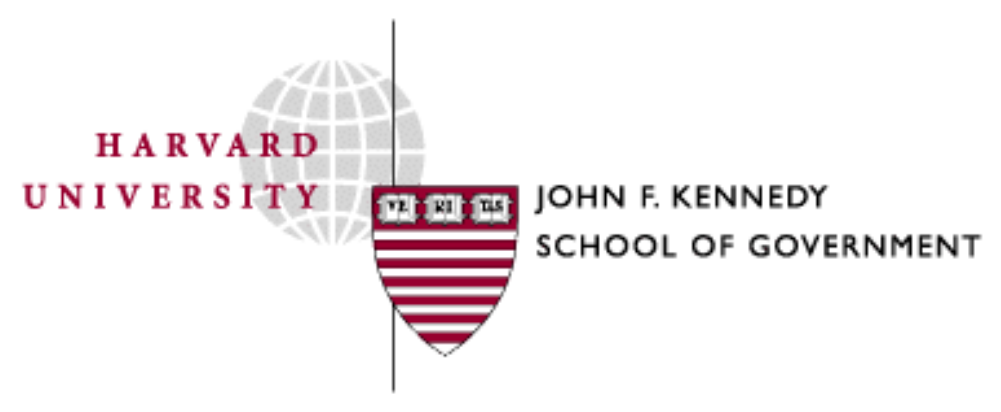

Faculty Research Working Papers Series

\title{
It Depends Who Is Asking and Who You Ask: Social Incentives for Sex Differences in the Propensity to Initiate Negotiation

\author{
Hannah Riley Bowles, Linda Babcock, and Lei Lai
}

July 2005

RWP05-045 belongs to the author(s). Papers may be downloaded for personal use only. 
It Depends Who Is Asking and Who You Ask

Social Incentives for Sex Differences in the Propensity to Initiate Negotiation

\author{
Hannah Riley Bowles \\ John F. Kennedy School of Government \\ Harvard University \\ 79 JFK Street, Cambridge, MA 02138 \\ tel: 6174964717 \\ fax: 6174963337 \\ email: hannah_bowles@harvard.edu
}

Linda Babcock and Lei Lai

H. John Heinz III School of Public Policy and Management

Carnegie Mellon University

Keywords: Gender, negotiation, sex differences, status 


\begin{abstract}
Two experiments show that sex differences in the propensity to initiate negotiations may be explained by differential treatment of men and women when they attempt to negotiate. In Experiment 1, participants evaluated candidates who either accepted compensation offers without comment or attempted to negotiate higher compensation. Men only penalized female candidates for attempting to negotiate whereas women penalized both male and female candidates. Perceptions of niceness and demandingness mediated these effects. In Experiment 2, participants adopted candidates' role in same scenario and assessed whether to accept the compensation offer or attempt to negotiate for more. Women were less likely than men to choose to negotiate when the evaluator was male, but not when the evaluator was female. This effect was mediated by women's nervousness about negotiating with male evaluators. This work illuminates how differential treatment may influence the distribution of organizational resources through sex differences in the propensity to negotiate.
\end{abstract}




\section{It Depends Who Is Asking and Who You Ask}

Social Incentives for Sex Differences in the Propensity to Initiate Negotiation

"There is no form of human excellence before which we bow with profounder deference than that which appears in a delicate woman... and there is no deformity in human character from which we turn with deeper loathing than from a woman forgetful of her nature, and clamorous for the vocation and rights of men."

Albert T. Bledsoe (1856, p. 224) ${ }^{1}$

Research on corporate managers suggests that women are less likely than men to use negotiation in upward influence attempts (Lauterbach \& Weiner, 1996). Other studies of broader populations indicate that women are less likely than men, in general, to initiate negotiations (Babcock, Gelfand, Small, \& Stayn, in press; Babcock \& Laschever, 2003). Women report greater anxiety than men about negotiation and are less likely than men to perceive situations as negotiable (Babcock, Gelfand, Small, \& Stayn, in press).

Conventional wisdom (e.g., "it pays to ask" and "the squeaky wheel gets the grease") suggests that, if women want the same resources and opportunities as men, then they should learn to seek out, rather than shy away from, opportunities to negotiate. For instance, one study of compensation negotiations by graduating professional school students found that women were significantly less likely than men to try to negotiate to improve upon their initial compensation offers. Only $7 \%$ of female students attempted to negotiate as compared to $57 \%$ of men. Those graduates who negotiated gained on average $7.4 \%$ over their initial offers (Babcock \& Laschever, 2003). Even small differences in starting salaries can lead to substantial 
compensation gaps over time (Bowles, Babcock, \& McGinn, in press; Gerhart \& Rynes, 1991). Women's reluctance as compared to men to initiate negotiations may be an important and underexplored explanation for the asymmetric distribution of resources, such as compensation, within organizations.

So, why would women let such opportunities pass? Maybe women need more training and practice in negotiation to help them get over their nervous feelings and to learn how to act more like the men when opportunities to negotiate arise. But, what if women's relative nervousness and hesitation about initiating negotiations has less to do with their negotiating ability than with the way they are treated when they attempt to negotiate? "Fix the women" solutions to gender issues often fail to take into consideration the gendered social context out of which sex differences in behavior emerge (Deaux \& Major, 1987; Ely \& Meyerson, 2000; Wade, 2001).

Society rewards and reinforces different types of behavior for men and women, and it is not always good advice for women act more like men to claim the same resources and privileges. Research on feminine modesty, for instance, shows that women tend to present themselves more modestly than do men (Daubman, Heatherington, \& Ahn, 1992; Gould \& Slone, 1982; Heatherington, Daubman, Bates, \& Ahn, 1993), and that a modest self-presentation style tends to undermine perceived competence, particularly as compared to those who self-promote in a stereotypically masculine way (Rudman, 1998). However, if women attempt to overcome this "deficiency" by behaving in a more masculine self-promoting manner, they are perceived as technically skilled but lacking in social competence. This lack of social competence then detracts from their perceived hireability (Rudman, 1998). Similarly, research on gender and leadership has found that female leaders who attempt to establish their authority in a traditionally masculine 
(e.g., authoritative or directive) manner are evaluated more harshly than their male peers (Eagly, Makhijani, \& Klonsky, 1992). Perhaps in response to this resistance, women have tended to develop a more participative leadership style, which is correspondent with prescriptive gender roles for women (Eagly \& Johnson, 1990) and more effective for them than traditionally male leadership styles (Eagly, Johannesen-Schmidt, \& van Engen, 2003; Eagly, Karau, \& Makhijani, 1995).

The current research explores the question of whether sex differences in the propensity to initiate negotiations may be explained by differential treatment of men and women when they attempt to negotiate. We examine whether women encounter more social resistance than do men when they attempt to negotiate for higher compensation and whether the sex of the evaluator moderates resistance to male and female negotiators. We investigate further whether women are less inclined than men to initiate compensation negotiations in those situations in which they are more likely to than men to encounter social resistance. In this way, we are able to illuminate how differential treatment of male and female negotiators may motivate sex differences in the propensity to initiate negotiations over resources, such as compensation.

\section{Initiation of Compensation Negotiations as a Status Violation}

Prescriptive stereotypes of appropriate masculine and feminine behavior stem from men's higher status as compared to women within society (Conway, Pizzamiglio, \& Mount, 1996; Eagly \& Steffen, 1984; Hoffman \& Hurst, 1990; Jackman, 1994; Meeker \& Weitzel-O'Neill, 1977; Ridgeway \& Bourg, 2004). Societies with more gender equity tend to espouse less sexist beliefs (Glick et al., 2000). Within the U.S., as the proportion of women in the workplace has grown and the gender segregation of occupations has declined, women have come to identify more with masculine personality traits (Spence \& Buckner, 2000; Twenge, 1997) and society has 
come to view women of today and tomorrow as more masculine than women of the past (Cejka \& Eagly, 1999; Diekman \& Eagly, 2000). Nevertheless, women are still expected to fulfill prescriptions of feminine niceness (e.g., warmth, kindness, sensitivity to the needs of others), which are emblematic of their subordinate status and therefore not fully compatible with all aspects of the masculine personality type (Jackman, 1994; Prentice \& Carranza, 2002; Ridgeway, 2001a; Rudman \& Glick, 2001).

In a recent test of contemporary college students' responses to two classic gender identity scales (Bem Sex Role Inventory by Bem, 1974; Personality Attributes Questionnaire by Spence \& Helmreich, 1978), Spence and Buckner (2000) found that women identified more strongly than men on all of the feminine items, but that men identified more strongly than women with only $41 \%$ of the masculine items. The majority of masculine items with which both men and women identified tended to relate to being active, independent and expressing one's own beliefs, whereas the items with which men identified more strongly than women tended to relate to being forceful, competitive and in charge. Rudman and Glick (2001) have argued that Spence and Buckman's findings reflect two distinct dimensions of the masculine stereotype: competence and dominance. The majority of masculine traits with which both men and women equally identify are consistent with the "competence" dimension of the masculine stereotype. The minority of items with which men identify more strongly than women represent the "dominance" dimension of the masculine stereotype. While both competence and dominance are associated with higher status group members (Berger, Webster, Ridgeway, \& Rosenholtz, 1986; Carli, LaFleur, \& Loeber, 1995), Rudman and Glick argue that the traits and behaviors associated with masculine "competence" present less of a contradiction with the prescriptive norms of feminine behavior than do the traits and behaviors associated with masculine "dominance." 
Warmth and competence is an attractive, non-threatening combination (Carli et al., 1995; Fiske, Cuddy, Glick, \& Xu, 2002). While a women who projects her competence in a purely stereotypically masculine manner runs a higher risk of social resistance than a similarly selfpresented man (Carli, 1990; Carli et al., 1995; Eagly et al., 1992; Rudman, 1998; Rudman \& Glick, 1999; Rudman \& Glick, 2001), women can effectively convey their competence and be as influential as men, if they soften their stereotypically masculine competence with feminine niceness (Carli et al., 1995; Meeker \& Weitzel-O'Neill, 1977; Ridgeway, 1982; Rudman \& Glick, 2001). For instance, research on social influence shows that women can have as much social influence as men, by ensuring that they appear friendly as well as task-oriented rather than purely task-oriented (Carli et al., 1995) or by communicating their concern for the collective rather than their personal self-interest (Meeker \& Weitzel-O'Neill, 1977; Ridgeway, 1982). By employing a complementary combination of masculine competence and feminine niceness, women can make substantive contributions within traditionally male domains without challenging the hierarchical structure of gender relations (Carli et al., 1995; Meeker \& WeitzelO'Neill, 1977; Ridgeway, 1982).

However, whereas women may temper resistance to their displays of masculine competence by combining them with stereotypically feminine behaviors, the display of masculine dominance directly contradicts the deferential and relational character of the feminine personality type. Displays of masculine dominance by women pose a direct challenge to the gender status hierarchy and therefore a greater social risk than do displays of masculine competence (Rudman \& Glick, 2001). 


\section{Hypotheses}

We propose that the initiation of compensation negotiations poses a challenge for women because it calls for a type of dominative masculine behavior (viz., the competitive assertion of one's self-interest) that contradicts the prescriptive norms of feminine behavior. More specifically, we hypothesize that the act of attempting to negotiate competitively for greater personal resources, such as higher compensation, violates prescriptions of feminine niceness and that that violation of prescriptive niceness engenders social resistance.

We hypothesize further that women's attempts to initiate negotiations over compensation, in particular, may be resisted for the substance of the claim as well as for the behavior inherent in the request. Men's relatively greater economic resources as compared to women's are a source of status for them within society (Ridgeway, 2001b; Weber, 1968), and the complementarity of masculine and feminine gender roles (i.e., men as providers and women as care-givers) justifies and reinforces the asymmetric distribution of resources, such as compensation, favoring men within society (Jackman, 1994; Jost \& Kay, 2005). As lower status group members making claims to the privileges of higher status group members, women are likely to appear inappropriately demanding or presumptuous if they attempt to negotiate for higher levels of compensation.

Research on gender and social influence suggests that women are more likely to face status constraints on their influence attempts when facing male as opposed to female evaluators (Carli, 1990; Deaux \& Major, 1987; Ridgeway \& Berger, 1986). This may be in part because women's status relative to men is more salient in mixed-sex than in same-sex interactions (Berger, Fisek, Norman, \& Zelditch, 1977; Deaux \& Major, 1987), but there is also evidence that women tend to have more status-attenuating (as opposed to status-enhancing) preferences than 
do men (Sidanius, Pratto, \& Bobo, 1994) and that female evaluators tend to hold men's and women's influence attempts to more similar standards than do male evaluators (Carli, 1990; Carli et al., 1995). We hypothesize that the sex of the evaluator will moderate the relative social risks for women as compared to men of attempting to negotiate for higher compensation, such that the relative risks for women as compared to men will be greater with male than with female evaluators.

Finally, we propose that sex differences in the propensity to initiate compensation negotiations will be greater in those circumstances in which men and women tend to face differential treatment when they attempt to negotiate. Therefore, assuming that women encounter more resistance than men when attempting to negotiate for higher compensation with male evaluators, we would expect women to be more reluctant than men to attempt to negotiate for higher compensation in the face of a male evaluator.

In sum, as illustrated vividly by the opening quote, if women are perceived to be "clamoring" for the same resources as men, they may lose the grace of their idealized feminine niceness and be rejected for demanding that which is not due to them. We propose further that sex differences in the propensity to initiate negotiations may be explained by differences in the way men and women are perceived and treated when they attempt to negotiate. In the following experiments we test these propositions and examine the role of the sex of the evaluator in shaping expectations about whether to negotiate and in providing social reinforcement for sex differences in negotiation behavior.

\section{Overview of Experiments}

We conducted a complementary set of experiments (Experiments 1 and 2) that tested for sex effects on both the likelihood of social resistance to negotiation attempts and on the 
propensity to initiate negotiations within the same negotiating context. In Experiment 1, participants adopted the role of senior managers in a corporation and evaluated internal candidates in a videotaped job placement interview. The candidates employed one of two alternative strategies for handling a potential opportunity for negotiation, which was the discussion of their compensation offer. One strategy involved simply acknowledging the compensation offer (no negotiation), and the other involved attempting to negotiate for higher compensation. We tested whether the sex of the candidate and the sex of the participant would influence participants' evaluations of the candidates' behavior. In Experiment 2, we reversed the participants' perspectives. This time, participants adopted the role of the job candidates and evaluated the same two alternative strategies used in Experiment 1 for how to handle the discussion of their compensation offer. We tested whether the sex of the participant and the sex of the evaluator would influence participants' feelings about whether to attempt to negotiate, their perceptions of the potential for negative social consequences if they attempted to negotiate, and whether they would choose the negotiation over the no-negotiation strategy. By coupling these two perspectives on the same situation, we were able to test whether the participants' propensity to initiate negotiations in Experiment 2 would reflect the differential treatment observed in Experiment 1.

\section{Experiment 1}

In Experiment 1, we tested for sex effects on the evaluation of negotiation behavior in a $2($ Sex of Candidate $) \times 2($ Sex of Evaluator $) \times 2$ (Initiate Negotiation: No Ask vs. Ask $)$ betweensubjects design. Participants adopted the perspective of a senior manager in a corporation and evaluated an internal candidate for a management position within their department based on his or her behavior in a videotaped interview. In the No Ask condition, candidates responded to a 
question about their salary and benefits offer by affirming that the information package had been received and was clear. In the Ask condition, the candidates responded to the same question by affirming that the information package had been received and was clear and then asking to be considered for higher compensation.

We predicted a three-way interaction effect of Sex of Candidate $\times$ Sex of Evaluator $\times$ Ask, such that the relative social cost for female as compared to male candidates for attempting to negotiate for higher compensation would be greater with male than with female evaluators. We predicted that male evaluators would perceive female candidates in the Ask vs. No Ask condition to be significantly less nice and more demanding and that perceived niceness and demandingness would mediate male evaluators' resistance to working with female candidates when they attempted to negotiate for higher compensation.

\section{Method}

\section{Participants}

The participants were 285 adults (105 men, 180 women). Participants signed up to complete a web-base survey called the Evaluation Study at one of two different websites that recruit experimental participants. The mean age was 31 years. Forty-five percent of the participants had management experience. Participants received $\$ 8$ for completing the online survey.

Procedure

Participants accessed the survey remotely by clicking on a link to the Evaluation Study website. After indicating their consent to participate in the study, the website directed the participants to a page of Background Information with links to a videotaped interview and the Evaluation Survey. The Background Information instructed participants to imagine they were 
senior managers in a corporation and informed them that their task was to evaluate an internal candidate for a management position in their department. The Background Information continued on to explain that the candidate was in the process of completing a management training program before being assigned to a more senior management position within the company and that the candidate (like all those being considered for management positions) had graduated from a top school and performed well in the training program. According to the Background Information, the participant (as senior manager) wanted people in the department who were good team players and who worked well with other people. Once participants had finished reviewing the Background Information, they were instructed to press a link to watch the interview.

The website randomly assigned participants to watch one of eight videos, so that each participant saw a head-and-shoulders shot of one of four candidates (two male, two female) who either accepted their compensation offer without comment or attempted to negotiate for a higher salary and bonus (No Ask vs. Ask). We recruited undergraduate actors to play the role of the candidate and coached the actors to enact the script as similarly as possible to one another.

The candidates responded to three questions in the videotape. The candidates' responses to the first two questions, which related to their management training and work experience, were identical across conditions. In response to the first two questions, the candidates explained that they had enjoyed and learned a lot in the training program and had some management experience running a school newspaper in college (approximately 2 minutes speaking time). In order to signal that the candidate was a good team player and worked well with other people, the response to the second question included statements such as, "I built a really strong team of people working together" and "I learned... how to get people motivated to do a good job." We 
embedded the experimental manipulation in the candidates' response to the third question about whether they had received their salary and benefits offer. Appendix A contains the wording of the third question and the actors' scripts for the No Ask and Ask conditions.

After watching the video, participants clicked on a link to the Evaluation Survey. The first step of the Evaluation Survey contained a list of characteristics adapted from Rudman and Glick’s (1999) social skills index. We used seven items from the social skills index (good listener, helpful, kind, likeable, sensitive to the needs of others, supportive, warm) and added four words that were characteristic of prescriptions of feminine niceness (agreeable, cooperative, modest, nurturing). We included another set of twelve words associated with demandingness (arrogant, cocky, demanding, dominating, obnoxious, overbearing, overconfident, presumptuous, pushy, self-centered, ungrateful, unreasonable). After rating the impressions created by the candidate, the participants indicated how likely they thought it was that the candidate had the communication and analytic skills to be an effective manager and how confident they were that the candidate would be an effective manager $(1=$ not at all, $7=$ extremely $)$. Finally, the participants rated how beneficial it would be for them to have this person working for them, how much they would enjoy having this person working for them, and how likely it was that they would hire this person $(1=$ not at all, $7=$ extremely $)$.

After the participants submitted their responses to the Evaluation Survey, the website directed them to an exit survey that contained manipulation checks, demographic questions and debriefing materials. The manipulation checks tested whether the participants knew the sex of the junior manager and how the junior manager had responded to the third question (i.e., asked for high salary, asked for bonus). The debriefing materials included a question about what the participants thought the study was about while they were participating in it. 


\section{Results}

All of the participants correctly identified the sex of the candidate, and none of the participants reported that they suspected that it was a gender-related study. We removed 38 cases because the participants failed to correctly identify how the candidate had responded to the third question. ${ }^{2}$ The data analyzed contained 247 cases (95 men, 152 women). We created a dummy variable equal to one if the candidate was female and zero if male (Female Candidate). We created a second dummy variable equal to one if the participant was female and zero if male (Female Evaluator). We created a final dummy variable equal to one if the candidate attempted to negotiate for higher compensation and zero if not (Ask). We used linear regressions to test the effects of sex of candidate, sex of evaluator and Ask on the evaluators' willingness to work with the candidate, the evaluators' perceptions of the impression created by the candidate, and whether the impressions mediated the evaluators' willingness to work with the candidate.

\section{Composite Variables}

Competence. We combined the three measures of how competent the evaluators perceived the candidates to be (i.e., communication skills, analytical skills and effective manager) into one composite indicator of perceived competence $(\alpha=.87)$.

Willingness to Work with the Candidate. We combined the three measures of the evaluators' willingness to work with the junior manager (i.e., would you hire this person, would you enjoy working with this person, would it be beneficial to have this person working for you) to create one composite dependent measure $(\alpha=.91)$.

Niceness and Demandingness. We conducted a principal components factor analysis of the impression items with promax rotation. This analysis revealed two factors. The first factor (eigenvalue $=12.32)$ consisted of 11 items (agreeable, cooperative, good listener, helpful, kind, 
likeable, modest, nurturing, sensitive to the needs of others, supportive, warm), which we combined into a composite indicator of perceived niceness $(\alpha=.94)$. The second factor (eigenvalue $=2.93$ ) consisted of 12 items (arrogant, cocky, demanding, dominating, obnoxious, overconfident, overbearing, presumptuous, pushy, self-centered, ungrateful, unreasonable), which we combined into a composite indicator of perceived demandingness $(\alpha=.96)$.

\section{Candidate Evaluation}

Competence. There was no significant difference in the perceived competence of the male and female candidates, male $M=4.23, S D=1.28$, female $M=4.46, S D=1.22, t(245)=$ $1.42, p=.16$. The Ask manipulation had no significant effect on the perceived competence of the male candidates, No Ask $M=4.39, S D=1.20$, Ask $M=4.04, S D=1.36, t(121)=1.51, p=.13$. The Ask manipulation also had no significant effect on the perceived competence of the female candidates, No Ask $M=4.60, S D=1.27$, Ask $M=4.32, S D=1.16, t(122)=1.29, p=.20$.

Willingness to work with the candidate. The top panel of Table 1 displays the results of the regression analyses of willingness to work with the candidate by Female Candidate, Female Evaluator and the Ask manipulation. As predicted, we observed a significant three-way interaction of Female Candidate $\times$ Female Evaluator $\times$ Ask $(B=1.64, t=2.41, p=.02)$. In order to facilitate the interpretation of the three-way interaction, the bottom two panels of Table 1 summarize the results of regression analyses of willingness to work with the candidates conducted separately for male and female evaluators.

In the regression for male evaluators, the coefficient on Ask is not significantly different from zero $(B=-0.34, t=-0.91, p=.36)$, indicating that male evaluators did not punish male candidates who negotiated for additional compensation. However, the coefficient on the interaction between Female Candidate and Ask is significantly negative $(B=-1.08, t=2.07, p=$ 
$.04)$, indicating that male evaluators were less likely to work with female candidates when they negotiated compared to when they did not. Table 2 displays means for the willingness to work with the candidates and effect sizes for the impact of initiating negotiation. For male evaluators (first row), the effect size $(d)$ of the Ask manipulation is small and statistically insignificant for male candidates but is large and statistically significant for female candidates.

The bottom panel Table 1 displays the regression for female evaluators. The coefficient on Ask was negative and significant $(B=-1.40, t=-4.65, p<.001)$ and the interaction between Female Candidate and Ask was not significantly different form zero $(B=0.56, t=1.32, p=.19)$, indicating that female evaluators penalized male candidates as much as female candidates for attempting to negotiate for higher compensation.

\section{Mediators}

Table 2 displays means by condition for perceived niceness and demandingness. We tested whether perceived niceness and demandingness would explain the participants' resistance to candidates who attempted to negotiate for higher compensation (i.e., female candidates by male and female evaluators and male candidates by female evaluators).

Niceness. As shown in Table 2, the evaluators' assessments of how nice they perceived the candidates to be produced the same patterns of means as their willingness to work with the candidate. Male evaluators perceived male candidates in the Ask condition to be just as nice as the male candidates in the No Ask condition $(t[45]=1.50, p=.14)$, whereas male evaluators perceived female candidates in the Ask as compared to No Ask condition to be significantly less nice $(t[46]=2.29, p=.03)$. Female evaluators perceived male candidates in the Ask as compared to No Ask condition to be significantly less nice $(t[74]=6.76, p<.001)$, and they perceived 
female candidates in the Ask as compared to No Ask condition to be significantly less nice (t[74] $=5.38, p<.001)$.

Table 3 contains a summary of regressions used in the mediation analyses. Perceived niceness partially mediated the effect of the Ask manipulation on both male and female evaluators' willingness to work with the female candidate, $z=2.19, p=.03$ for male evaluators and $z=4.82, p<.001$ for female evaluators (Sobel, 1982). As can be seen by comparing the regressions in columns 1 and 2 in each of the top two panels of Table 3 , when niceness is added to the regression equation, the magnitude of the Ask coefficient declines significantly (from -.50 to -.29 for male evaluators and from -.29 to -.18 for female evaluators). However, niceness does not fully explain the effect of the Ask manipulation on evaluators' willingness to work with the female candidates. The coefficient on Ask in both regressions remains statistically significant when niceness is included in the regression. Perceived niceness fully mediated the effect of the Ask manipulation on female evaluators' willingness to work with the male candidate, $z=5.44, p$ $<.001$ (Sobel, 1982). As shown in the first two columns of the bottom panel of Table 3, the coefficient on Ask falls to insignificance when niceness is added to the equation.

Demandingness. As shown in the bottom panel of Table 2, the evaluators perceived candidates in Ask vs. No Ask condition to be significantly more demanding in all conditions ( $t$ s $>4.84, p s<.001)$. Perceived demandingness fully mediated the effect of the Ask manipulation on the participants' willingness to work with the female candidate, $z=3.81, p<.001$ for male evaluators and $z=4.12, p<.001$ for female evaluators (Sobel, 1982). As can be seen by comparing columns 1 and 3 of the female candidate regressions in the top two panels of Table 3 , the coefficient on Ask falls to insignificance when demandingness is added to the equation. Perceived demandingness also fully mediated the effect of the Ask manipulation on female 
evaluators' willingness to work with the male candidates, $z=5.55, p<.001$. As shown in the bottom panel of Table 3, the coefficient on Ask falls to insignificance when demandingness is added to the regression.

\section{Discussion}

The results of Experiment 1 supported the hypothesis that the relative social risk to women of attempting to negotiate for higher compensation as compared to men would be greater with male than with female evaluators. Attempting to negotiate for higher compensation had no effect on male evaluators' willingness to work with male candidates, while it had a significantly negative effect on their willingness to work with female candidates. Mediation analyses further supported our propositions that the attempt to negotiate for higher compensation poses a greater social risk for women than for men with male evaluators, because it violates status-based prescriptions of appropriate feminine behavior by the contradicting the norms of feminine niceness and making women appear inappropriately demanding. Male evaluators perceived male candidates who attempted to negotiate for higher compensation to be just as nice as those who did not. Male evaluators found male candidates who attempted to negotiate for higher compensation to be significantly more demanding than those who did not, but attempting to negotiate for higher compensation had no effect on male evaluators' willingness to work with a male candidate. In contrast, male evaluators were significantly less inclined to work with female candidates who attempted to negotiate for higher compensation as compared to those who did not, both because they perceived them to be less nice and because they perceived them to be inappropriately demanding.

It warrants note that perceived competence was not a liability for the female candidates. The evaluators rated the female candidates to be as competent as the male candidates, and the 
Ask manipulation had no significant effect on the perceived competence of either male or female candidates. It was the violation of behavioral norms as opposed to concerns about their ability to be effective managers that demotivated the male evaluators from working with the female candidates who asked. These results reinforce the proposition that, while we have come to accept women's masculine competence, women still face status-based behavioral constraints in workplace contexts that preclude them from dominative behaviors such as the explicitly competitive pursuit of one's self-interest (Rudman \& Glick, 2001).

Whereas for male evaluators the sex of the candidate had a significant interactive effect with the Ask manipulation, the sex of the candidate had no significant effect on female evaluators' judgments of the candidates' asking behavior. Female evaluators were less inclined to work with any candidate who attempted to negotiate for higher compensation, and a lack of perceived niceness and perceived demandingness explained female evaluators' resistance to male as well as female candidates. These results suggest that female evaluators' concerns about the candidates' asking behavior and how nice or demanding they appeared to be were not gendered, in the sense that they were not holding women to a higher standard of niceness than men nor were they evaluating demanding behavior as less appropriate for women than for men. However, it may have been gendered to the extent that it was because of their socialization as women that female evaluators perceived the initiation of compensation negotiations to be inappropriate. These effects of sex of evaluator in Experiment 1 follow a similar pattern to results observed in previous research on gender and social influence (Carli et al., 1995), in which female evaluators weighted the both likeability and perceived competence in their judgments of male and female candidates whereas male evaluators weighted likeability more heavily in their judgments of female than of male candidates. 
In sum, from the perspective of the female candidates, attempting to negotiate was socially risky regardless of the sex of the evaluator. Both male and female evaluators were significantly more inclined to work with a female candidate if she accepted her salary and benefits offer without comment than if she attempted to negotiate for higher compensation. For male candidates, on the other hand, attempting to negotiate for higher compensation posed no social risk with a male evaluator. Attempting to negotiate was only a problem if the evaluator was female. These results suggest that women should be more hesitant than men about attempting to negotiate with a male evaluator, but that there should be not sex difference in the propensity to initiate negotiations with a female evaluator. In Experiment 2, we instructed participants to adopt the perspective of the candidate in this situation and tested this prediction.

\section{Experiment 2}

In Experiment 2, we tested for sex effects on the propensity to initiate negotiations in a 2 $($ Sex of Candidate $) \times 2$ (Sex of Evaluator $)$ experimental design. The scenario and interview scripts were identical to those used in Experiment 1. However, in Experiment 2, the participants adopted the perspective of the candidate rather than the evaluator. The task for the participants was to prepare for the job placement interview. The participants reviewed two potential strategies for how to respond in the likely event that the interviewer asked about their salary and benefits offer. One plan called for affirming that the package had been received and was clear (No Ask plan). The other plan called for affirming that the package had been received and was clear, but also asking to be considered for higher compensation (Ask plan). All participants reviewed both plans. The background information also informed participants that there was a particular department to which they hoped to be assigned and provided a brief description of the 
head of that department. In order to test for effects by sex of evaluator, we manipulated whether the head of the department for whom the junior manager wanted to work was a man or a woman.

We tested whether the sex of the participant and the sex of the evaluator would influence participants' feelings about whether to attempt to negotiate, their perceptions of the potential for negative social consequences if they attempted to negotiate, and whether they would choose to negotiate. Based on the results of Experiment 1 and our original hypotheses, we predicted that female participants would be less inclined than male participants to use the Ask vs. No Ask plan with a male evaluator. We predicted that female (as compared to male) participants would feel more nervous about using the Ask vs. No Ask plan and would anticipate more negative social consequences when facing a male evaluator and that nervousness and the anticipation of negative social consequences would mediate their propensity to choose the Ask vs. No Ask plan.

The results of Experiment 1 also suggested that male participants should be less inclined to use the Ask vs. No Ask plan with a female than with a male evaluator. We tested whether male candidates would feel more nervous, anticipate more negative consequences and be less inclined to choose the Ask vs. No Ask plan when facing a female as compared to a male evaluator and whether nervousness and the anticipation of negative social consequences would mediate the effect of sex of evaluator on their propensity to initiate compensation negotiations.

Because our hypotheses were motivated by the proposition that sex effects on the propensity to negotiate are motivated by social feedback that negotiators receive based on their biological sex, we thought we should explore the alternative hypothesis that sex effects on the propensity to negotiate are a function of the negotiator's gender identity (i.e., the extent to which the negotiator identifies with masculine or feminine personality traits) and that sex serves simply as a proxy for gender identification. In order to explore this alternative hypothesis, we asked 
participants to complete a "Personality Profile Survey" following their assessment of the two plans, which included masculine and feminine traits from the Bem Sex Role Inventory (BSRI) (Bem, 1981). We tested whether the extent to which participants identified with masculine and feminine personality traits would mediate the effect of sex of participant on the likelihood of using the Ask vs. No Ask plan.

\section{Method}

\section{Participants}

The participants were 314 adults (165 men, 149 women) recruited from the website of an experimental research laboratory to participate in an Interview Preparation Study. The median age of the participants was 21 years $(\operatorname{Min}=18, \operatorname{Max}=64)$. Eighty percent of the participants were full-time university students. The median part-time or full-time work experience was three years. Participants received $\$ 15$ for completing the survey.

\section{Procedure}

After obtaining the participants' consent to participate in the study, the experimenter distributed paper packets containing background information on the interview preparation scenario. The background material instructed participants to imagine that they had just completed a management training program in preparation for a more senior management position within their company. According to the background materials, the participants were about to participate in a placement interview to determine the department to which they would be assigned. Participation in the study involved preparing for that interview.

Ask vs. No Ask Plan. The background information presented participants with three questions that the interviewer was likely to ask. The background information indicated that the participants had already decided on their answers to the first two questions, which related to their 
experience in the training program and any work experience that they had managing people. The background information contained the prepared answers to those questions, which were identical to the responses provided by the candidates in Experiment 1. The task for participants was to decide between two alternative answers (i.e., Plan A or Plan B) to the third question, which related to their salary and benefits offer from the company. Plan A was the No Ask script used in the Experiment 1, and Plan B was the Ask script used in Experiment 1.

Sex of Evaluator. The background information informed the participants that the senior manager they really wanted to work for was Sydney Pollard, who was known to hire people who are good team players and who work well with other people. In order to manipulate the sex of the evaluator (Sydney), the background information and survey questions referred to Sydney either as a man or as a woman and with corresponding male or female pronouns.

Dependent Measures. After reviewing the background materials, the participants completed an online Interview Preparation Survey in which they assessed each of the plans. Participants rated each plan individually in terms of how they would feel about using the plan and whether they anticipated negative social consequences from using the plan. Participants rated on a scale of 1-7 ( $1=$ disagree completely, 7 = agree completely $)$ how embarrassed, comfortable, nervous, relaxed, and anxious they would feel using each of the plans. Participants answered two questions on a scale 1-7 ( $1=$ disagree completely, $7=$ agree completely $)$ whether they thought a man (or woman) like Sydney Pollard would not want to hire or work with them if they used either plan. Finally, participants rated which plan they would be more likely to use relative to the other on a scale of 1-7 ( 1 = I would be much more likely to use [the No Ask plan], $7=$ I would be much more likely to use [the Ask plan]). After submitting their responses to the Interview Preparation Survey, the participants completed a second online Personality Profile 
Survey. This survey included the 30 items from the BSRI short form. A final online exit survey contained manipulation checks, demographic questions and debriefing materials. The manipulation checks tested whether the participants knew the difference between Plan A and Plan B and the sex of the evaluator (Sydney). The debriefing materials included a question about what they thought the study was about while they were participating in it.

\section{Results}

We removed 13 cases because the participants failed to provide correct answers on the manipulation checks. We removed 8 cases because the participants said that they had suspected the study was about gender in hiring or gender in negotiation. The data analyzed contained 293 cases (155 men, 138 women).

In order to test whether the sex of the participant or sex of the evaluator influenced participants' relative assessments of the two options, we created two dummy variables, Female Participant and Female Evaluator, which were equal to one if the participant or evaluator, respectively, was female and to zero if male. We used linear regressions to test for the effects of sex of participant and sex of evaluator on the likelihood of using the Ask vs. No Ask plan and to test for mediation effects.

Use of Plan A vs. Plan B

As shown in the top panel of Table 4, there was a significant, negative coefficient on Female Participant in the regression for the likelihood of using the Ask vs. No Ask plan $(B=-$ $0.65, t=-2.22, p=.03$ ), which was qualified by a marginally significant interaction effect of Female Participant $\times$ Female Evaluator $(B=0.75, t=1.84, p=.07)$. As depicted in Figure 1, when the evaluator was male, women were significantly less inclined than men to use the Ask vs. No Ask plan, male participant $M=2.53, S D=1.94$, female participant $M=1.88, S D=1.61$, 
$t(138)=2.14, p=.03, d=.36$. When the evaluator was female, men were as likely as women to use the Ask vs. No Ask plan, male participant $M=2.22, S D=1.69$, female participant $M=2.31$, $S D=1.65, t(151)=-0.35, p=.72, d=.05$. Contrary to the results of Experiment 1 , men were not more likely to use the Ask vs. No Ask plan when the evaluator was male vs. female, $t(153)=$ $1.07, p=.29$. Across all conditions, the mean rating of the likelihood of using the Ask vs. No Ask plan was significantly lower than the indifference point of 4 between the two options ( $t$ s $>$ $6.63, p<.001)$, indicating that participants on average favored the No Ask over the Ask plan.

\section{Mediators}

Nervousness. We reverse coded the two positive feeling items (i.e., comfortable, relaxed) and created mean composite indicators of how "nervous" the participants felt about using the Ask and No Ask plans (No Ask $\alpha=.83$, Ask $\alpha=.87$ ). On average, the participants felt significantly less nervous about using the No Ask as compared to Ask Plan, No Ask $M=2.22$, $S D=1.25$, Ask $M=5.66, S D=1.24, t(292)=-27.87, p<.001$. Neither the sex of the participant nor the sex of the evaluator had any significant effect on the participants' nervousness about using the No Ask plan, $t \mathrm{~s}<0.70, p s>.48$.

The middle panel of Table 4 displays the regression for nervousness with using the Ask plan. $^{3}$ There was a significant, positive coefficient on Female Participant $(B=0.69, t=3.33, p=$ .001 ), indicating that women were more nervous on average than men about using the Ask plan. Means analysis revealed, however, that the effect of sex of participant was only significant when the evaluator was male. As depicted in Figure 1, when the evaluator was male, women were significantly more nervous than men about using the Ask plan, male participant $M=5.30, S D=$ 1.28 , female participant $M=5.99, S D=1.14, t(138)=-3.33, p=.001, d=.57$. When the evaluator was female, women were slightly but not significantly more nervous than men about 
using the Ask plan, male $M=5.56, S D=1.26$, female $M=5.85, S D=1.16, t(151)=-1.49, p=$ $.14, d=.24$.

Nervousness about using the Ask plan fully mediated the effect of sex of participant on the willingness to use the Ask vs. No Ask plan with male evaluators, $z=3.01, p<.01$ (Sobel, 1982). Regressions of the likelihood of using the Ask vs. No Ask plan when the evaluator was male showed that the coefficient on Female Participant was reduced from .18 $(t=-2.14, p=.03)$ to $-.04(t=-0.47, p=.64)$ when nervousness about the Ask plan was added to the regression.

Contrary to the results of Experiment 1, men were not more nervous about using the Ask plan when the evaluator was female as opposed to male, $t(153)=1.24, p=.22$.

Anticipated Backlash from Using the Ask vs. No Ask Plan. We combining the two items about whether using a plan would make the evaluator not want to hire or work them into mean composite indicators of "anticipated backlash" from using the Ask and No Ask plans (No Ask $\alpha$ $=.81$, Ask $\alpha=.87)$. On average, the participants anticipated significantly less backlash from using the No Ask as compared to the Ask Plan, No Ask $M=2.90, S D=1.50$, Ask $M=4.87, S D$ $=1.60, t(292)=-13.14, p<.001$. Neither the sex of the participant nor the sex of the evaluator had any significant effect on anticipated backlash from using the No Ask plan, $t \mathrm{~s}<1.41, p \mathrm{~s}>$ .16.

The bottom panel of Table 4 displays the regression for anticipated backlash from using the Ask plan. ${ }^{4}$ There was a significant, positive coefficient on Female Evaluator $(B=0.62, t=$ $2.44, p=.02$ ), which was qualified by a significant, negative interaction effect of Female Participant $\times$ Female Evaluator $(B=-0.93, t=-2.51, p=.01)$. Consistent with the results of Experiment 1, men anticipated significantly more backlash when the evaluator was female than when the evaluator was male (male evaluator $M=4.58, S D=1.71$, female evaluator $M=5.20$, 
$S D=1.33, t[153]=-2.53, p=.01, d=.41)$, whereas women anticipated as much backlash from a male as from a female evaluator (male evaluator $M=5.00, S D=1.65$, female evaluator $M=$ $4.69, S D=1.65, t[136]=1.10, p=.27, d=.19)$.

Because the sex of the participant had no significant effect on anticipated backlash, anticipated backlash was not a candidate for mediation of the effect of sex of participant on the likelihood using the Ask vs. No Ask plan when the evaluator was male.

Identification with Masculine and Feminine Personality Traits. Female participants identified more strongly than did male participants with the feminine personality traits on the BSRI, female $M=5.56, S D=.78$, male $M=5.26, S D=.90, t(291)=3.10, p<.01, d=.36$. There was no sex difference in the participants' identification with the masculine personality traits, female $M=4.96, S D=.82$, male $M=5.08, S D=.85, t(291)=1.32, p=.18, d=.14$. There was no significant correlation between participants' ratings on the femininity and masculinity scales, $r=.08, p=.18$

There was no significant correlation between how much the participants identified with feminine personality traits and the likelihood using the Ask vs. No Ask plan, $r<.05, p=.46$. However, the more participants identified with masculine personality traits, the more likely they were to use the Ask vs. No Ask plan $(r=.13, p=.02)$. Because femininity was not predictive of the likelihood of using the Ask vs. No Ask plan and there was no sex difference in the participants' masculinity scores, the participants' femininity and masculinity scores were not candidates for mediation of the effect of sex of participant on the likelihood of using the Ask vs. No Ask plan.

Given the potential for participants to identify strongly with one, both or neither of the scales (i.e., to be masculine or feminine identified, androgynous or undifferentiated, respectively) 
(Bem, 1974), we tested whether the degree to which a participant identified with the personality traits on one scale relative to the other might be more predictive than the main effects of either scale. Regression analyses showed no significant effects for the masculinity score, femininity score or their interaction on the likelihood of using the Ask vs. No Ask plan when the evaluator was male $(t \mathrm{~s}<1.14, p>.25)$. Therefore, the relative degree of identification with masculine vs. feminine personality traits was also not a candidate for mediation of the effect of sex of participant on the likelihood of using the Ask vs. No Ask plan when the evaluator was male.

\section{Discussion}

The results of Experiment 2 supported our hypotheses with regard to the effect of sex of participant on the propensity to initiate compensation negotiations. When the evaluator was female, women were as inclined as men to attempt to negotiate for higher compensation. However, when the evaluator was male, women were significantly less inclined than men to attempt to negotiate for higher compensation. Mediation analyses showed that women were significantly more nervous than men about attempting to negotiate for higher compensation when the evaluator was male, and that nervousness explained their reticence to choose the negotiation option. Contrary to our predictions, women did not anticipate more backlash than men when the evaluator was male. These results suggest that the women's greater hesitation (as compared to men) to act was informed more by their gut instinct than a conscious cost-benefit calculus based upon the anticipated social consequences of initiating negotiation. The results of Experiment 1 confirm that the women's feelings conveyed valid information: women had good reason to feel more nervous than men when initiating compensation negotiations with a male evaluator. Future research should take advantage of developments in the study of emotions in 
decision making (e.g., Damasio, 1994) and explore the relative influence of emotions and conscious reasoning in the reinforcement of status-based behavioral norms.

The results of Experiment 1 suggested that men might be more reluctant to attempt to negotiate for higher compensation with a female as compared to a male evaluator. The male participants in Experiment 2 did anticipate more backlash from a female than from a male evaluator, but they were not more nervous about attempting to negotiate with a female vs. male evaluator nor were they more reluctant to negotiate with a female vs. male evaluator.

Finally, we tested for possible mediating effects of gender identity in order to explore the alternative hypothesis that sex effects on the propensity to negotiate might be related to gender identification as opposed to differential treatment based on biological sex. Reinforcing Bem's (1974) seminal work, there was no correlation between participants' masculinity and femininity scores on the BSRI. Consistent with the results of recent studies of gender identification, the female participants identified more strongly with the set of feminine personality traits than did the male participants, but there was no sex difference in participants' identification with the set of masculine personality traits (Spence \& Buckner, 2000; Twenge, 1997). There was no direct correlation between the participants' femininity scores and their propensity to negotiate. The higher the participants' masculinity scores, the more likely they were to choose the negotiation option. However, gender identification did not explain the effect of sex of participant on the propensity to negotiate when the evaluator was male. These results further support the proposition that sex effects on the propensity to negotiate are motivated by differential treatment based on biological sex rather than gender-based behavioral preferences. 


\section{General Discussion}

We posed the question at the beginning of this paper of whether women's greater reticence as compared to men about attempting to negotiate for resources, such as higher compensation, could be explained by the differential treatment of male and female negotiators. The results of these experiments suggest that the answer to this question is yes. Our empirical results showed that male evaluators punish women, but not men, for attempting to initiate compensation negotiations (Experiment 1) and that, with male evaluators, women were less likely than men to initiate compensation negotiations (Experiment 2). Female evaluators, on the other hand, were as resistant to attempts to negotiate for higher compensation by male candidates as they were to attempts by female candidates (Experiment 1), and there was no sex difference in the propensity to initiate compensation negotiations with female evaluators (Experiment 2).

Whether our participants' behavior was optimal, in terms of weighing the actual social and economic costs and benefits of initiating compensation negotiations, remains an open question. The benefits of initiating negotiations in this type of context would obviously include the expected compensation gains, and the costs would include the risks of undermining potentially important working relations and missing out on desirable work opportunities. If the expected economic gains were large enough to outweigh the social costs, then the rational course of action would be to initiate negotiations, in spite of the social risks. If the social costs and their long-term career implications outweighed the benefits of higher compensation, then reticence would be the more prudent choice. We cannot claim, based on our research, that either men or women are initiating negotiation too much or too little. We show with this research that women's disinclination relative to men to initiate negotiation over resources, such as compensation, may be traced to the higher social costs that they face when doing so. 
The results of the mediation analyses in Experiment 1 supported the proposition that women encounter more resistance than men when initiating compensation negotiations with male evaluators because male evaluators perceive such behavior on the part of women as a status violation. Men were significantly more inclined to work with nicer and less demanding women who accepted their compensation offers without comment than they were with those who attempted to negotiate for higher compensation, even though they perceived the women who spoke up to just be as competent as the women who demurred. In contrast, the attempt to negotiate for higher compensation had no influence on men's willingness to work with the male candidates.

This freedom for men to negotiate with other men has potentially important implications for the distribution of resources and opportunities within organizations, given that, in most organizations, those who control organizational resources and opportunities for advancement tend to be men. This phenomenon could even help to explain social inequities such as the gender wage gap and glass ceiling. If women are justifiably less inclined than men to initiate negotiations with men, then they may have fewer opportunities to increase their compensation and promotion potential.

It warrants emphasis that it is not clear from the results of these experiments that men consciously resist women's attempts to initiate negotiation. The results of Experiment 2 suggested that the female participants were more reticent about negotiating than were male participants when the evaluator was male because the idea of doing so made them more nervous and not because they anticipated more backlash. It warrants further investigation whether the male evaluators' resistance to women who attempted to negotiate was motivated by a feeling of aversion or discomfort rather than by a conscious decision that such behavior by women should 
be punished. Research on the challenges to women of breaking the glass ceiling suggests that aspiring female executives perceive more gender-based restrictions on their potential for advancement than do male CEOs, and that many male CEOs think that women should take more initiative to signal their interest in critical developmental experiences (Ragins, Townsend, \& Mattis, 1998). Future research should explore whether raising awareness about the systemic sources and consequences of the gender gap in the initiation of negotiation might mitigate the perceived and actual risks for women of attempting to negotiate with male evaluators.

While the female evaluators were more equitable in their treatment of male and female candidates, they were intolerant of attempts to negotiate for higher compensation. Women penalized both men and women for lacking in niceness and being overly demanding when they attempted to negotiate. It may be the case that women are socialized through their own negotiation attempts and through observing the negotiating attempts of other women to perceive the initiation of negotiation as socially unacceptable behavior. Even if what they have learned is that the initiation of negotiations over issues such as compensation is unacceptable for women, they may still resent and reject behavior by men that would not be permitted for women. Negotiation is a fundamental form of social interaction within organizations, and a potentially important mechanism for the retention and attraction of talented labor. Future research is warranted to understand better why female evaluators are so resistant to attempts to negotiate and of the costs and benefits of inhibiting negotiations over issues such as compensation.

One noteworthy limitation of this experimental design was the artificiality of the negotiation and no-negotiation scripts. The participants in Experiment 2 were more inclined in general to use the plan in which they accepted their compensation offer without comment than the plan that called for negotiating for a higher salary and bonus. If the participants had been able 
to choose their own words, it is possible that more of them would have chosen to negotiate and that women and men would have presented themselves differently (Barron, 2003). If male and female candidates had been able to choose their own words and self-presentation style, the participants in Experiment 1 might have evaluated them differently as well (Carli, 1990).

We weighed this limitation, however, against the benefit of enabling us to test the effects of sex of participant, sex of evaluator and gender identification on a specific set of behavioral choices. One criticism of previous research on gender and the propensity to initiate negotiation is that it left open to question whether reported sex differences in the frequency of negotiation might be associated with sex differences in the interpretation of what constitutes a negotiation. Indeed, previous research has shown that women are significantly less likely than men to perceive situations as opportunities to negotiate (Babcock et al., in press). Providing participants with a choice of whether to negotiate or not ensured that they recognized the potential for negotiation within the situation. The scripts also enabled us to test in Experiment 1 how evaluators would perceive men and women enacting the precise behaviors that the participants in Experiment 2 assessed.

In sum, our research shows that, in certain situations, there are higher social risks for women than for men in initiating negotiation and that these risks may help to explain why women are less likely than men under certain circumstances to initiate negotiations. Recent developments in the study of gender in negotiation show that gender effects in negotiation are highly situational (e.g., Bowles et al., in press; Kray \& Thompson, in press; Walters, Stuhlmacher, \& Meyer, 1998). Future research should explore the extent to which the effects observed in these studies are moderated by other types of situational factors beyond the sex of 
the evaluator, such as the type of resource to be negotiated, the negotiator's influence style (Carli et al., 1995), or the evaluators' impression formation motivations (Rudman, 1998).

\section{Conclusion}

The current research contributes both to the study of gender in negotiation and to the study of social outcomes in negotiation. Whereas previous research has focused on internal motivations for sex differences in the propensity to negotiate (Babcock et al., in press), this set of studies demonstrates clearly that men and women face different social incentives when deciding whether or not to initiate negotiations over issues such as compensation. These findings have important implications for the teaching and practice of negotiation, because they show that onesize-fits-all prescriptions may not turn out to be "best practice" for both male and female negotiators. If women face greater social costs from initiating negotiation, then it might not be good advice for women to initiate negotiations as frequently as men.

For the theoretical advancement of the study of gender in negotiation, this work helps to expand our understanding of how sex effects in negotiation may be reinforced through differential treatment of men and women, as well as through the activation of sex-based performance stereotypes (e.g., Kray, Galinsky, \& Thompson, 2002; Kray, Thompson, \& Galinsky, 2001) and other gender schema (Bowles et al., in press). This research also reinforces the importance of studying the social as well as economic outcomes of negotiation (Morris, Larrick, \& Su, 1999), because the social costs of engaging in certain negotiating behaviors may not outweigh economic benefits.

Finally, this research contributes more broadly to research on gender in organizations, because it demonstrates how sex-based behavioral expectations may contribute to the asymmetric distribution of resources and opportunities within organizations. It also illuminates 
some of the limits to behavioral prescriptions for women for resolving systemic gender issues. This research suggests that the gender gap in the initiation of negotiation cannot be resolved simply by encouraging women to speak up more. Addressing this issue requires an understanding of the situational circumstances that motivate sex differences in the propensity to negotiate and a set of prescriptions that alter the behavior of evaluators as well as negotiators. 


\section{References}

Babcock, L., Gelfand, M., Small, D., \& Stayn, H. (in press). Gender differences in the propensity to initiate negotiations. In D. D. Cremer, M. Zeelenberg \& J. K. Murnighan (Eds.), Social Psychology and Economics. Mahwah, NJ: Lawrence Erlbaum.

Babcock, L., \& Laschever, S. (2003). Women don't ask. Princeton, NJ: Princeton University Press.

Barron, L. (2003). Ask and you shall receive? Gender differences in beliefs about requests for a higher salary. Human Relations, 56(6), 635-663.

Bem, S. L. (1974). The measurement of psychological androgyny. Journal of Consulting and Clinical Psychology, 42(2), 155-162.

Bem, S. L. (1981). Bem Sex-Role Inventory. San Francisco, CA: Consulting Psychologists Press.

Berger, J., Fisek, M. H., Norman, R. Z., \& Zelditch, M. E. (1977). Status characteristics and social interaction: An expectation-states approach. New York: Elsevier.

Berger, J., Webster, M., Jr., Ridgeway, C. L., \& Rosenholtz, S. J. (1986). Status cues, expectations and behaviors. In E. Lawler (Ed.), Advances in group processes. Greenwich, CT: JAI Press.

Bledsoe, A. T. (1856). An essay on liberty and slavery. Philadelphia: J. B. Lippincott.

Bowles, H. R., Babcock, L., \& McGinn, K. L. (in press). Constraints and triggers: Situational mechanics of gender in negotiation. Journal of Personality and Social Psychology.

Carli, L. L. (1990). Gender, language, and influence. Journal of Personality and Social Psychology, 59(5), 941-951. 
Carli, L. L., LaFleur, S. J., \& Loeber, C. C. (1995). Nonverbal behavior, gender, and influence. Journal of Personality and Social Psychology, 68(6), 1030-1041.

Cejka, M. A., \& Eagly, A. H. (1999). Gender-stereotypic images of occupations correspond to the sex segregation of employment. Personality and Social Psychology Bulletin, 25(4), 413-423.

Conway, M., Pizzamiglio, M. T., \& Mount, L. (1996). Status, communality, and agency: Implications for stereotypes of gender and other groups. Journal of Personality and Social Psychology, 71(1), 25-38.

Damasio, A. R. (1994). Descartes' error: Emotion, reason, and the human brain. New York: G.P. Putnam.

Daubman, K. A., Heatherington, L., \& Ahn, A. (1992). Gender and the self-presentation of academic achievement. Sex Roles, 27(3-4), 187-204.

Deaux, K., \& Major, B. (1987). Putting gender into context: An interactive model of genderrelated behavior. Psychological Review, 94(3), 369-389.

Diekman, A. B., \& Eagly, A. H. (2000). Stereotypes as dynamic constructs: Women and men of the past, present, and future. Personality and Social Psychology Bulletin, 26(10), 1171.

Eagly, A. H., Johannesen-Schmidt, M. C., \& van Engen, M. L. (2003). Transformational, transactional and laissez-faire leadership styles: A meta-analysis comparing men and women. Psychological Bulletin, 129(4), 569-591.

Eagly, A. H., \& Johnson, B. T. (1990). Gender and leadership style: A meta-analysis. Psychological Bulletin, 108(2), 233-256.

Eagly, A. H., Karau, S. J., \& Makhijani, M. G. (1995). Gender and the effectiveness of leaders: A meta-analysis. Psychological Bulletin, 117(1), 125-145. 
Eagly, A. H., Makhijani, M. G., \& Klonsky, B. G. (1992). Gender and the evaluation of leaders: A meta-analysis. Psychological Bulletin, 111(1), 3-22.

Eagly, A. H., \& Steffen, V. J. (1984). Gender stereotypes stem from the distribution of women and men into social roles. Journal of Personality and Social Psychology, 46(4), 735-754.

Ely, R. J., \& Meyerson, D. E. (2000). Theories of gender in organizations: A new approach to organizational analysis and change. Research in Organizational Behavior, 22, 103-151.

Fiske, S. T., Cuddy, A. J. C., Glick, P., \& Xu, J. (2002). A model of (often mixed) stereotype content: Competence and warmth respectively follow from perceived status and competition. Journal of Personality and Social Psychology, 82(6), 878-902.

Gerhart, B., \& Rynes, S. (1991). Determinants and consequences of salary negotiations by male and female MBA graduates. Journal of Applied Psychology, 76(2), 256-262.

Glick, P., Fiske, S. T., Mladinic, A., Saiz, J. L., Abrams, D., Masser, B., et al. (2000). Beyond prejudice as simple antipathy: Hostile and benevolent sexism across cultures. Journal of Personality and Social Psychology, 79(5), 763-775.

Gould, R. J., \& Slone, C. G. (1982). The "feminine modesty" effect: A self-presentational interpretation of sex differences in causal attribution. Personality and Social Psychology Bulletin, 8(3), 477-485.

Heatherington, L., Daubman, K. A., Bates, C., \& Ahn, A. (1993). Two investigations of "female modesty" in achievement situations. Sex Roles, 29(11-12), 739-754.

Hoffman, C., \& Hurst, N. (1990). Gender stereotypes: Perception or rationalization? Journal of Personality and Social Psychology, 58(2), 197-208.

Jackman, M. R. (1994). The velvet glove: Paternalism and conflict in gender, class, and race relations. Berkeley, CA: University of California Press. 
Jost, J. T., \& Kay, A. C. (2005). Exposure to benevolent sexism and complementary gender stereotypes: Consequences for specific and diffuse forms of system justification. Journal of Personality and Social Psychology, 88(3), 498-509.

Kray, L. J., Galinsky, A., \& Thompson, L. (2002). Reversing the gender gap in negotiations: An exploration of stereotype regeneration. Organizational Behavior and Human Decision Processes, 87(2), 386-409.

Kray, L. J., \& Thompson, L. (in press). Gender stereotypes and negotiation performance. In B. M. Staw \& R. Kramer (Eds.), Research in Organizational Behavior (Vol. 26). Greenwich, CT: JAI Press.

Kray, L. J., Thompson, L., \& Galinsky, A. (2001). Battle of the sexes: Gender stereotype confirmation and reactance in negotiations. Journal of Personality and Social Psychology, 80(6), 942-958.

Lauterbach, K. E., \& Weiner, B. J. (1996). Dynamics of upward influence. Leadership Quarterly, 7(1), 87-107.

Meeker, B. F., \& Weitzel-O'Neill, P. A. (1977). Sex roles and interpersonal behavior in taskoriented groups. American Sociological Review, 42(1), 91-105.

Morris, M. W., Larrick, R. P., \& Su, S. K. (1999). Misperceiving negotiation counterparts: When situationally determined bargaining behaviors are attributed to personality traits. Journal of Personality \& Social Psychology, 77(1), 52-67.

Myrdal, G. (1994). An American dilemma: The Negro problem and modern democracy. New York: Harper \& Brothers. 
Prentice, D. A., \& Carranza, E. (2002). What women and men should be, shouldn't be, are allowed to be, and don't have to be: The contents of prescriptive gender stereotypes. Psychology of Women Quarterly, 26(4), 269-281.

Ragins, B. R., Townsend, B., \& Mattis, M. (1998). Gender gap in the executive suite: CEOs and female executives report on breaking the glass ceiling. The Academy of Management Executive, 12, 28-42.

Ridgeway, C. L. (1982). Status in groups: The importance of motivation. American Sociological Review, 47(1), 76-88.

Ridgeway, C. L. (2001a). Gender, status, and leadership. Journal of Social Issues, 57(4), 637655.

Ridgeway, C. L. (2001b). How do status beliefs develop? The role of resources and interactional experiences. In J. Jost \& B. Major (Eds.), The psychology of legitimacy: Emerging perspectives on ideology, justice and intergroup relations (pp. 357-377). Cambridge, England: Cambridge University Press.

Ridgeway, C. L., \& Berger, J. (1986). Expectations, legitimation, and dominance behavior in task groups. American Sociological Review, 51(5), 603-617.

Ridgeway, C. L., \& Bourg, C. (2004). Gender as status: An expectation states theory approach. In A. H. Eagly, A. E. Beall \& R. J. Sternberg (Eds.), The psychology of gender (pp. 217241). New York: Guliford Press.

Rudman, L. A. (1998). Self-promotion as a risk factor for women: The costs and benefits of counterstereotypical impression management. Journal of Personality and Social Psychology, 74(3), 629-645. 
Rudman, L. A., \& Glick, P. (1999). Feminized management and backlash toward agentic women: The hidden costs to women of a kinder, gentler image of middle managers. Journal of Personality and Social Psychology, 77(5), 1004-1010.

Rudman, L. A., \& Glick, P. (2001). Prescriptive gender stereotypes and backlash toward agentic women. Journal of Social Issues, 57(4), 743-762.

Sidanius, J., Pratto, F., \& Bobo, L. (1994). Social dominance orientation and the political psychology of gender: A case of invariance? Journal of Personality and Social Psychology, 67(6), 998-1011.

Sobel, M. E. (1982). Asymptotic intervals for indirect effects in structural equations models. In S. Leinhart (Ed.), Sociological methodology (pp. 290-312). San Francisco: Jossey-Bass.

Spence, J. T., \& Buckner, C. E. (2000). Instrumental and expressive traits, trait stereotypes, and sexist attitudes. Psychology of Women Quarterly, 24(1), 44-62.

Spence, J. T., \& Helmreich, R. L. (1978). Masculinity and femininity: Their psychological dimensions, correlates, and antecedents. Austin: University of Texas Press.

Twenge, J. M. (1997). Changes in masculine and feminine traits over time: A meta-analysis. Sex Roles, 36(5-6), 305-325.

Wade, M. E. (2001). Women and salary negotiation: The costs of self-advocacy. Psychology of Women Quarterly, 25(1), 65-76.

Walters, A. E., Stuhlmacher, A. F., \& Meyer, L. L. (1998). Gender and negotiator competitiveness: A meta-analysis. Organizational Behavior and Human Decision Processes, 76(1), 1-29.

Weber, M. (1968). Economy and society (E. Frischoff, Trans.). In G. Roth \& C. Wittich (Eds.), Economy and society: An outline of interpretive sociology. New York: Bedminister Press. 


\section{Appendix A}

Question 3. By now you must have received the salary and benefits offer from the company. Is there anything else you would like us to keep in mind as we consider your management placement?

No Ask Condition. Yes, I received the salary and benefits package. The benefits information was very clear. Geographically, I am totally unconstrained. I am happy to work anywhere, as long as I have got interesting stuff to do.

Ask Condition. Yes, I received the salary and benefits package. The benefits information was very clear. Geographically, I am totally unconstrained. I am happy to work anywhere, as long as I have got interesting stuff to do. What was not clear to me, however, was whether that salary represented the top of the pay range. I understand that there is a range in terms of how much junior managers are paid in their first placement. I think I should be paid at the top of that range. This is really important to me; I think I deserve it. I also would like to be eligible for an end-ofyear bonus. I know performance bonuses are not standard for junior managers, but I would certainly be more motivated if I could look forward to a performance bonus at the end of the year. I am thinking of something in the 25 to $50 \%$ of salary range. Not doubling my salary or anything. And, listen, I don't care if it's in cash or stocks - and I promise you I'll earn it. So, those are the two things that I am asking with regard to my compensation: (1) paying me at the top of the junior manager salary range and (2) providing me with an end of year, $20-50 \%$ of salary performance bonus.

Note: In the instructions for participants in Experiment 2, we labeled the Ask and No Ask condition scripts Plan A and Plan B, respectively. 


\section{Footnotes}

${ }^{1}$ As quoted by Jackman (1994, p. 79), who obtained the quote from Myrdal (1994, p. 1074).

${ }^{2}$ The website required participants to launch the video before proceeding to the Evaluation Survey, but it did not prevent participants from closing down the video midstream. We suspect that these participants did not watch the entire video.

${ }^{3}$ Including the No Ask nervousness composite as an independent variable in regression analyses of the Ask nervousness composite had no significant influence on the effects of sex of participant or sex of evaluator.

${ }^{4}$ Including the No Ask anticipated backlash composite as an independent variable in the regression analyses of the Ask anticipated backlash composite had no significant influence on the effects of sex of participant or sex of evaluator. 
Table 1

Experiment 1: Regression Analysis of Willingness to Work with Candidate by Sex of Evaluator, Sex of Candidate and Ask Condition for All Evaluators, Male Evaluators and Female Evaluators

\begin{tabular}{|c|c|c|c|c|}
\hline Source & $B$ & $S E B$ & $\beta$ & $R^{2}$ \\
\hline \multicolumn{5}{|c|}{ All Evaluators $(N=247)$} \\
\hline Female Candidate & $0.76^{*}$ & .36 & $.27^{*}$ & .17 \\
\hline Female Evaluator & 0.39 & .32 & .14 & \\
\hline Ask & -0.34 & .38 & -.12 & \\
\hline Female Candidate $\times$ Female Evaluator & -0.72 & .46 & -24 & \\
\hline Female Candidate $\times$ Ask & $-1.08^{*}$ & .53 & $-.33^{*}$ & \\
\hline Female Evaluator $\times$ Ask & $-1.06^{*}$ & .48 & $-.35^{*}$ & \\
\hline Female Evaluator $\times$ Female Candidate $\times$ Ask & $1.64^{*}$ & .68 & $.42^{*}$ & \\
\hline \multicolumn{5}{|c|}{ Male Evaluators $(N=95)$} \\
\hline Female Candidate & $0.76^{*}$ & .35 & $.28^{*}$ & .15 \\
\hline Ask & -0.34 & .37 & -.13 & \\
\hline Female Candidate $\times$ Ask & $-1.08^{*}$ & .46 & $-.34^{*}$ & \\
\hline \multicolumn{5}{|c|}{ Female Evaluators $(N=152)$} \\
\hline Female Candidate & 0.04 & .29 & .01 & .17 \\
\hline Ask & $-1.40^{* * *}$ & .30 & $-.49^{* * *}$ & \\
\hline Female Candidate $\times$ Ask & 0.56 & .43 & .17 & \\
\hline
\end{tabular}
${ }^{*} p<.05 .{ }^{* * *} p<.001$. 
Table 2

Experiment 1: Means of Ask and No Ask Conditions for Willingness to Work with Candidate and Perceived Niceness and Demandingness by Sex of Candidate and Sex of Evaluator

\begin{tabular}{|c|c|c|c|c|c|c|}
\hline & \multicolumn{3}{|c|}{ Male Candidate } & \multicolumn{3}{|c|}{ Female Candidate } \\
\hline & No Ask & Ask & & No Ask & Ask & \\
\hline \multirow[t]{2}{*}{ Sex of Evaluator } & $M$ & $M$ & $d$ & $M$ & $M$ & $d$ \\
\hline & \multicolumn{6}{|c|}{ Willingness to Work with Candidate } \\
\hline \multirow[t]{2}{*}{ Male } & 4.10 & 3.75 & .27 & 4.85 & 3.43 & $1.14^{* * *}$ \\
\hline & $(1.07)$ & $(1.53)$ & & $(1.27)$ & $(1.22)$ & \\
\hline \multirow[t]{3}{*}{ Female } & 4.49 & 3.09 & $1.16^{* * *}$ & 4.53 & 3.68 & $0.60^{* *}$ \\
\hline & $(1.03)$ & $(1.38)$ & & $(1.48)$ & $(1.33)$ & \\
\hline & \multicolumn{6}{|c|}{ Niceness } \\
\hline \multirow[t]{2}{*}{ Male } & 4.18 & 3.77 & .44 & $4.63 \mathrm{a}$ & $3.92_{b}$ & $0.66^{*}$ \\
\hline & $(0.81)$ & $(1.08)$ & & $(1.01)$ & $(1.13)$ & \\
\hline \multirow[t]{3}{*}{ Female } & 4.66 & 3.18 & $1.41^{* * *}$ & 4.82 & 3.67 & $1.23^{* * *}$ \\
\hline & $(0.90)$ & $(1.00)$ & & $(0.96)$ & $(0.91)$ & \\
\hline & \multicolumn{6}{|c|}{ Demandingness } \\
\hline \multirow[t]{2}{*}{ Male } & 3.57 & 5.13 & $1.43^{* * *}$ & 3.02 & 4.85 & $1.93^{* * *}$ \\
\hline & $(0.99)$ & $(1.22)$ & & $(1.06)$ & $(0.81)$ & \\
\hline \multirow[t]{2}{*}{ Female } & 2.86 & 5.35 & $2.06^{* * *}$ & 2.82 & 4.88 & $1.77^{* * *}$ \\
\hline & $(1.24)$ & $(1.17)$ & & $(1.22)$ & $(1.10)$ & \\
\hline
\end{tabular}

Note: We report standard deviations of the means in parentheses below the means.

${ }^{*} p=.03 .{ }^{* *} p=.01{ }^{* * *} p<.001$. 
Table 3

Regression Analyses of Effect of Ask Manipulation on Willingness to Work with Candidate controlling for Perceived Niceness and Demandingness

Regressions Models for Female Candidates with Male Evaluators $(N=48)$

Ask

\begin{tabular}{ccc}
1 & 2 & 3 \\
\hline$-.50^{* * *}$ & $-.29^{* *}$ & -.02
\end{tabular}

Nice

$.67^{* * *}$

Demanding

$-.69^{* * *}$

Adjusted $R^{2}$

.13

.60

.35

Regressions Models for Female Candidates with Female Evaluators $(N=76)$

Ask

\begin{tabular}{ccc}
1 & 2 & 3 \\
\hline$-.29^{* * *}$ & $-.18^{*}$ & .14
\end{tabular}

Nice

$.89^{* * *}$

Demanding

Adjusted $R^{2}$

.25

.64

.55

Regressions Models for Male Candidates with Female Evaluators $(N=76)$

Ask

\begin{tabular}{cc}
1 & 2 \\
\hline$-.51^{* * *}$ & -.01 \\
& $.80^{* * *}$
\end{tabular}

Demanding

Adjusted $R^{2}$

.25

.64

.55

Note. Coefficients are standardized betas.

${ }^{*} p<.05 .{ }^{* *} p<.01 .^{* * *} p<.001$. 
Table 4

Experiment 2: Regression Analyses of Likelihood of Using Ask vs. No Ask Plan, Nervousness about Using Ask Plan and Anticipated Backlash from Using Ask Plan ( $\mathrm{N}=293)$

\begin{tabular}{|c|c|c|c|c|}
\hline Source & $B$ & $S E B$ & $\beta$ & $R^{2}$ \\
\hline \multicolumn{5}{|c|}{ Likelihood of Using Ask vs. No Ask Plan } \\
\hline Female Participant & $-0.65^{*}$ & .29 & -.19 & .02 \\
\hline Female Evaluator & -0.31 & .28 & -.09 & \\
\hline Female Participant $\times$ Female Evaluator & $0.75^{+}$ & .41 & .19 & \\
\hline \multicolumn{5}{|c|}{ Nervousness about Using Ask Plan } \\
\hline Female Participant & $0.69^{* *}$ & .21 & .28 & .05 \\
\hline Female Evaluator & 0.25 & .20 & .10 & \\
\hline Female Participant $\times$ Female Evaluator & -0.40 & .29 & -.14 & \\
\hline \multicolumn{5}{|c|}{ Anticipated Backlash from Using Ask Plan } \\
\hline Female Participant & 0.42 & .27 & .13 & .03 \\
\hline Female Evaluator & $0.62^{*}$ & .26 & $.19^{*}$ & \\
\hline Female Participant $\times$ Female Evaluator & $-.93^{*}$ & .37 & $-.25^{*}$ & \\
\hline
\end{tabular}
${ }^{+} p<.10 .{ }^{*} p<.05 .{ }^{* * *} p<.001$. 


\section{Figure Caption}

Figure 1. Experiment 2: Mean likelihood of using the Ask vs. No Ask plan and nervousness about using the Ask plan by sex of participant and sex of evaluator. Higher scores on 1-7 scale indicate greater likelihood of using the Ask as opposed to No Ask plan and greater nervousness about using the Ask plan. Asterisks indicate significant mean differences between male and female participants.

$* p<.05$. 


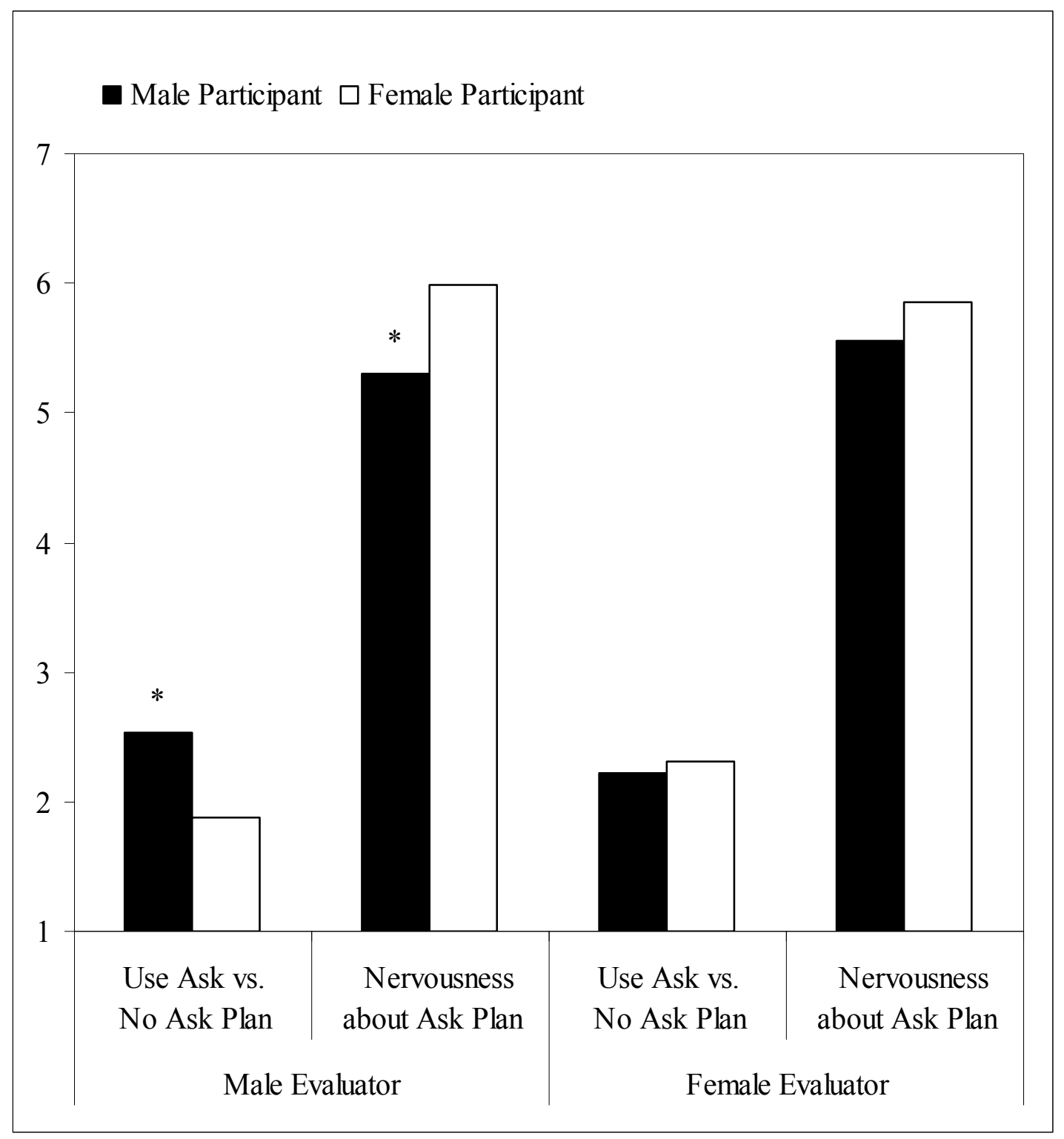

